\title{
Semantic Analysis and Thematic Annotation
}

\begin{abstract}
This contribution aims at investigating some methods, resources and tools devoted to the semantic analysis and the thematic annotation. The first part, devoted to the paradigmatic axis, describes available lexico-semantic resources for the classical languages, which belong to accomplished or on-going projects. Starting from Minozzi's Latin WordNet, the structure of multilingual lexico-semantic networks mapped on the original (American English) Princeton WordNet will be discussed and criticized. The automated procedures to create the basis for a new Ancient Greek WordNet from bilingual dictionaries (mainly: the LSJ) will be illustrated and the on-going project named Homeric Greek WordNet, validated by students and scholars, will be presented. Furthermore, the difficulties to map the conceptual nodes related to the ancient world on a modern semantic network will be discussed. The second part of the contribution, devoted to the syntagmatic axis, is focused on the semantic and thematic annotation of classical and biblical texts. The top-down approach to the annotation of themes and motifs in the Memorata Poetis Project is illustrated and pros and cons are discussed. In that project, devoted to the study of multilingual and multicultural intertextuality, a taxonomy of thematic labels established a priori is shared by all the members of the project. Finally, the bottom-up approach of Euporia is discussed. In this approach, folksonomies are created by the annotators, and the labels are grouped and organized in ontologies a posteriori, during an incremental process of revision.
\end{abstract}

\section{Introduction}

The notion of "dead languages" is deceiving: it is better to focus the attention on the complex relations between continuous and discontinuous traditions. Ancient Greek and classical Latin evolved towards modern languages through continuous, oral traditions and partially survive through discontinuous, literary traditions: ${ }^{1}$ the linguistic resources discussed in this chapter are based only on the latter.

1 See Mondin (2014).

Federico Boschetti, Istituto di Linguistica Computazionale "A. Zampolli”, CNR, Pisa

๑ Open Access. ( 2019 Federico Boschetti, published by De Gruyter. (c) BY-Nc-ND This work is licensed under a Creative Commons Attribution-NonCommercial-NoDerivatives 4.0 International License. https://doi.org/10.1515/9783110599572-018 
When the transmission of linguistic knowledge, interrupted by calamitous events or just by a progressive decline in interest, is revitalized through a renewed focus on ancient literatures, i.e. in written texts that do not correspond to the current language of the native speakers, we must be aware of the wide discrepancy between the communicative competence of the sender of the literary message and the competence of the new receiver. The communicative competence involves not only linguistic, but also extra-linguistic aspects of the communication, such as the socio-cultural context in which the linguistic act (spoken or written) is performed: the notion of communicative competence has been introduced by Hymes (1966) precisely to overtake the dichotomy between linguistic competence and linguistic performance proposed by Chomsky (1965).

Even when we are in front of a genuine text, such as (under certain conditions) an epigraph, not corrupted by errors due to the transmission along the centuries, what we can recognize objectively, unequivocally, is just the signifier (signifiant, according to Saussure) layer, not the signified (signifié) layer. Textual meaning is always open to multiple interpretations and the hermeneutic space is wider according to the distance between the communicative competence of the message addresser and the competence of the addressee.

In this chapter we present digital resources and computational instruments to study ancient Greek and Latin words from a semantic point of view and to investigate classical texts from a thematic point of view. Section 2 is devoted to semantic analysis from three different perspectives. Distributional semantics is based on quantitative methods applied to textual corpora, in order to recognize semantic similarities among words that share similar contexts. WordNets are lexico-semantic resources based on information extracted from monolingual or bilingual dictionaries, in which words with the same meaning are grouped and associated to conceptual nodes that establish various semantic relations (e.g. hypernymy/hyponymy, or holonymy/meronymy) with other conceptual nodes. Finally, the Dynamic Lexicon is a lexical resource based on the alignment of ancient Greek and Latin texts with their translations into modern languages, such as English. Section 3 is devoted to the thematic analysis of classical (and modern) literary texts, by following different methodologies. Topic modeling is based on automated procedures for the identification of word/document clusters. By applying a top-down approach, intertextual relations are identified by human annotators among multilingual texts. On the contrary, by applying a bottom-up approach, patterns relevant for an interdisciplinary study of ancient texts (e.g. from a philological and anthropological perspective) are observed. 


\section{Semantic analysis}

Semantic analysis concerns the paradigmatic axis, even if it can exploit the syntagmatic axis for dealing with contextual information necessary to determine the word meaning. In this section two different approaches are discussed: the first one is based on the assumption that meaning is self-contained in textual corpora, because semantic similarity is latent behind the noisy variety of lexical choices. The second one is based on the assumption that bilingual dictionaries can be used to group together ancient Greek or Latin synonyms that share the same translation.

\subsection{Distributional semantics}

Distributional Semantics is based on the so called "distributional hypothesis" formulated by Firth (1957, 11): "You shall know a word by the company it keeps". According to this hypothesis, the word meaning is inferable by the contexts in which the word is used, i.e. by the other words of the documents in which it occurs. In order to calculate the similarity, it is necessary to create a vector space based on matrices of word co-occurences and apply statistical or computational methods to reduce the original, high dimensional space to a lower dimensional space with less information noise. ${ }^{2}$ In order to reduce the dimensions, Singular Value Decomposition is applied or, more recently, Recurrent Neural Networks are used. ${ }^{3}$

\subsubsection{Synchronic perspective}

As described by Boschetti (2018), the exploration of semantic spaces can be applied both to an entire corpus or to consistent subcorpora divided by genres (e.g. Epics, Tragedy, Philosophy, etc.). Semantic similarities due to the cooccurrence in similar contexts are identified by the proximity in the reduced vector space but they are not labeled: they can be synonyms, antonyms, hyper-/hyponyms or co-hyponyms, holo-/meronyms or co-meronyms, etc. As relevant examples, we will observe in the semantic space of the Ancient Greek corpus two case studies: co-hyponyms and antonyms.

2 See Lenci (2008).

3 See Mikolov (2013). 
Abstract terms that belong to traditional and highly repeated lists, such as virtues, feelings or emotions are easily clustered. We are interested to explore how are grouped virtues that constitute traditional paradigms, such as faith, hope and charity, compared to other positive qualities, such as úyícı, soundness.

As shown in Figure 1, clusters are sharply defined. On the right side of the plot we find some physical virtues frequently mentioned by ancient philosophers and writers. On the left side of the plot are distributed the seven virtues of the Christian tradition, clearly divided in two groups: the theological virtues

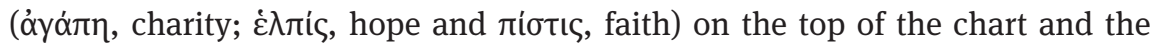

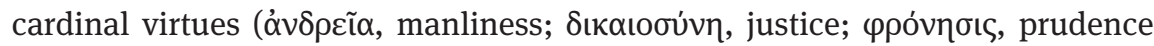
and $\sigma \omega \varphi \rho o \sigma u ́ v \eta$, temperance) on the bottom part of the chart.

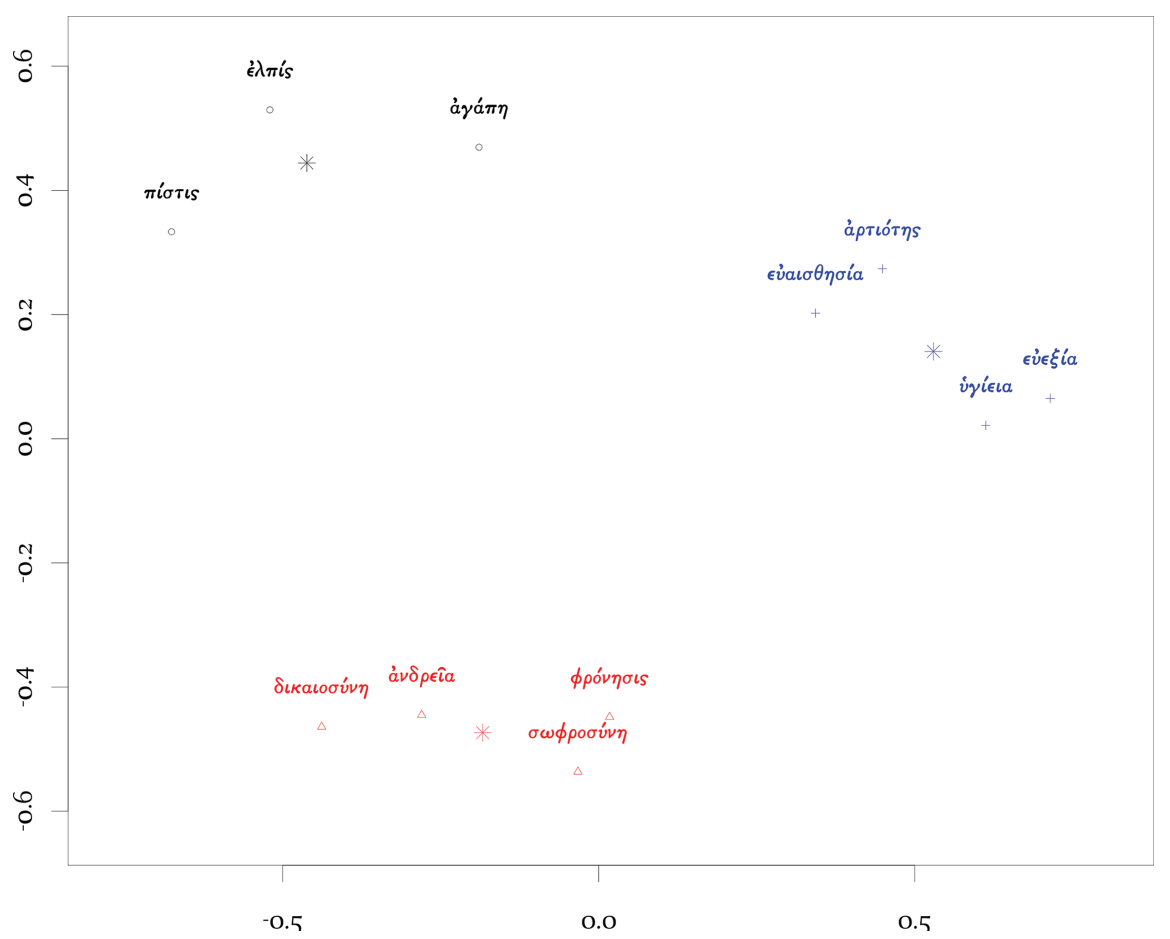

Figure 1: Semantic spaces: clusters of virtues.

Antonyms appear in similar contexts, in which opposite properties of the same terms are expressed, in particular when the couple of antonyms is constituted by adjectives that can occur with a restricted selection of names. 
As shown in Figure 2, tight proximity in the semantic space is observed for do-

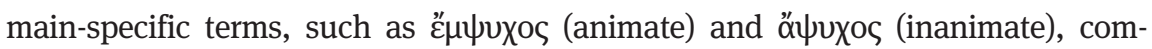
monly used in philosophical and medical texts. On the contrary, couples of

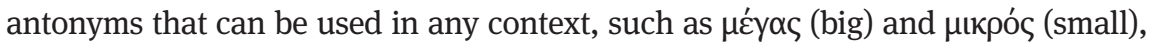
are more spaced.

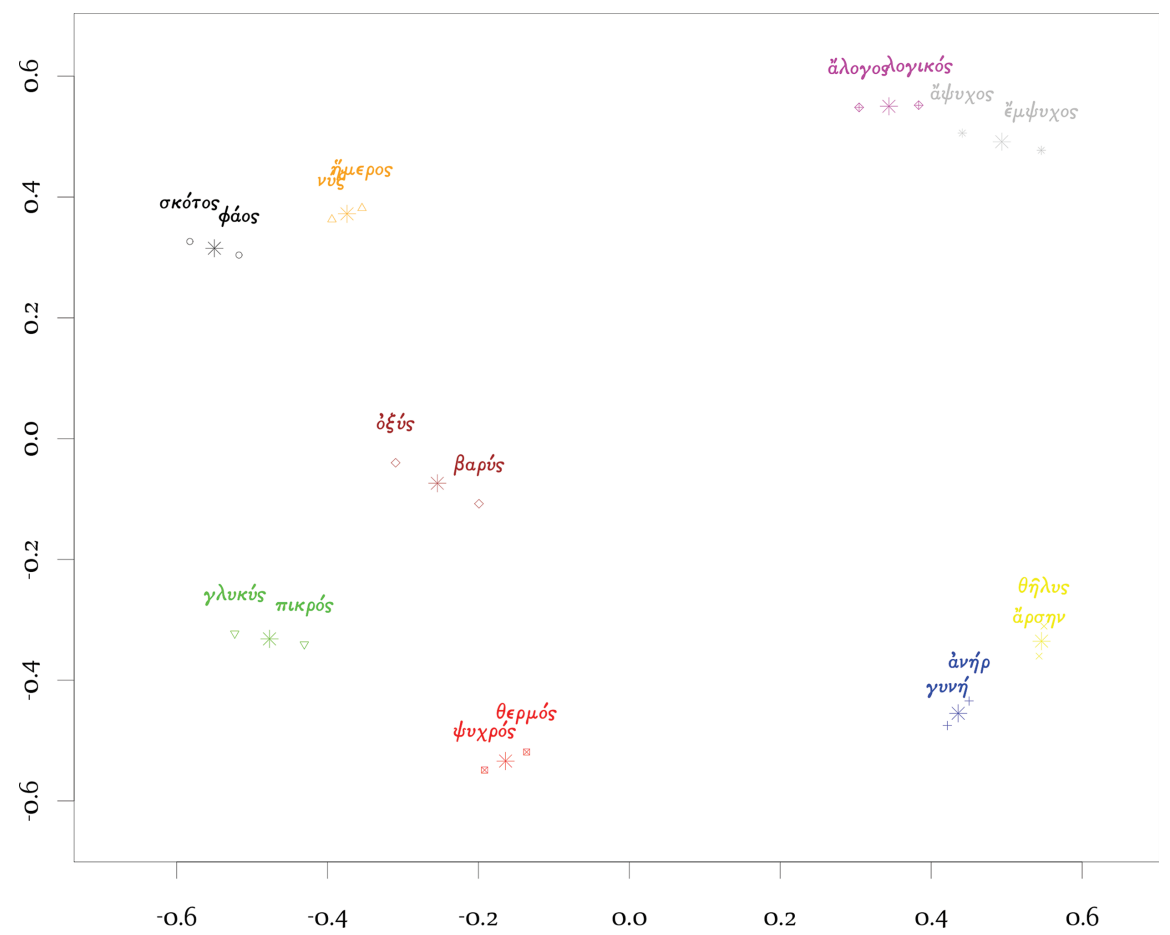

Figure 2: Semantic spaces: clusters of antonyms.

The identification of semantic similarity, combined with other linguistic information, such as frequency, diachronic distribution, genre distribution, etc. is useful to evaluate textual variants, in order to provide evidence that one word could be a trivial gloss for the other (lectio facilior). Finally, it is worth to note that O' Donnell (2005) applied these exploratory methods to the Greek of the New Testament.

\subsubsection{Diachronic perspective}

A large corpus of literary texts distributed along the centuries, such as the corpus of the entire ancient Greek Literature, can be chronologically partitioned 
according to historical periodizations. Semantic spaces constructed on the different subcorpora can show the semantic shift of relevant terms. For example, be-

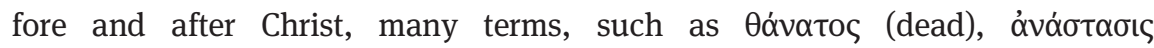
(resurrection) and $\alpha \theta \alpha v \alpha \sigma i \alpha$ (immortality), sensitively change their semantic associations. $^{4}$

\subsection{WordNets}

WordNets are lexico-semantic resources, in which the terms belonging to the open parts of speech (nouns, verbs, adjectives and adverbs) are grouped into sets of synonyms (called synsets) associated to conceptual nodes, which are described by a gloss. Words are interlinked by lexical relations, such as derivation (e.g. style / stylish) or antonymy (i.e. the relation between the contraries: e.g. big / small) and conceptual nodes are interlinked by semantic relations, such hypernymy / hyponymy (i.e. the relations between general and specific terms: e.g. container / bottle), holonymy / meronymy (i.e. the relations between compound and component: e.g. charriot / wheel).

The original project, usually called Princeton WordNet (PWN, available at https://wordnet.princeton.edu) in order to be distinguished by its derivatives, aimed at the creation of a lexical database for English, useful for computational linguists and cognitive scientists. ${ }^{5}$ Along the last decades many initiatives have extended PWN, in order to create an interrelated network of multilingual lexico-semantic resources. The Global WordNet Association (http://globalwordnet. org) provides a platform for discussing, sharing and connecting multilingual wordnets created by independent organizations.

EuroWordNet (EWN) ${ }^{6}$ (http://projects.illc.uva.nl/EuroWordNet/) and MultiWordNet (MWN) ${ }^{7}$ (http://multiwordnet.fbk.eu) are authoritative examples for modern (e.g. Italian, Spanish or Romanian) and ancient (e.g. Latin) languages.

In EWN and in MWN conceptual nodes of the new languages are aligned to the conceptual nodes of PWN by different philosophies, which are well expressed by Pianta et al. (2002, 1):

There are at least two models for building a multilingual wordnet. The first model, adopted within the EuroWordNet project, consists of building language specific wordnets

4 See Rodda (2017) and Boschetti (2018).

5 See Fellbaum (1998).

6 See Vossen (1998).

7 See Pianta et al. (2002). 
independently from each other, trying in a second phase to find correspondences between them (Vossen, 1998). The second model, adopted within MultiWordNet (MWN), consists of building language specific wordnets keeping as much as possible of the semantic relations available in the Princeton WordNet (PWN). This is done by building the new synsets in correspondence with the PWN synsets, whenever possible, and importing semantic relations from the corresponding English synsets; i.e., we assume that if there are two synsets in PWN and a relation holding between them, the same relation holds between the corresponding synsets in the new language.

\subsubsection{Latin WordNet}

Latin WordNet (LWN), developed at the University of Verona by Minozzi (2009), is part of the MultiWordNet Project. After the automated extraction of LatinEnglish couples from bilingual dictionaries and the projection on the PWN conceptual network, synsets have been manually validated. According to the model adopted by MWN, the conceptual structure of PWN constitutes the backbones for the synsets of the other languages. With modern western languages the correspondence is quite tight, but ancient languages are the expression of different conceptualizations. MWN has some mechanisms to afford this issue: the creation of new conceptual nodes, peculiar to a specific language, that in English can be expressed by a periphrasis (lexical gap); the linkage of words to a PWN conceptual node more general (a hypernym) or more specific (a hyponym); the implicit suppression of semantic relations among intermediate conceptual nodes.

This last case is exemplified in Figure 3, which is a screenshot captured from the MWN website, related to the hypernyms of the Latin term aquila in its different senses. For the first sense (eagle as bird of pray), PWN follows the complete taxonomy with the indication, in English, of the phylum cordate and the subphylum vertebrate, whereas the current version of LWN does not associate any lexical values to the intermediate conceptual nodes between animal and avis. Considering that MWN has not a diachronic perspective and that the Linnean taxonomy is expressed in Latin, the flatten hierarchy [aquila] $<$ [ales, avis, volucris] < [animal, animalis, bellua, bestia, pecus], which is suitable for the ancient conceptualization, could be enlarged in a future version of LWN with the intermediate synsets related to the phylum (cordata) and related to the subphylum (vertebrata).

In many cases LWN accepts modern senses, in agreement with the modus operandi of the Lexicon Recentis Latinitatis. ${ }^{8}$ Accordingly, for instance, cliens can have the meaning of "any computer that is hooked up to a computer

8 See Egger (2004). 


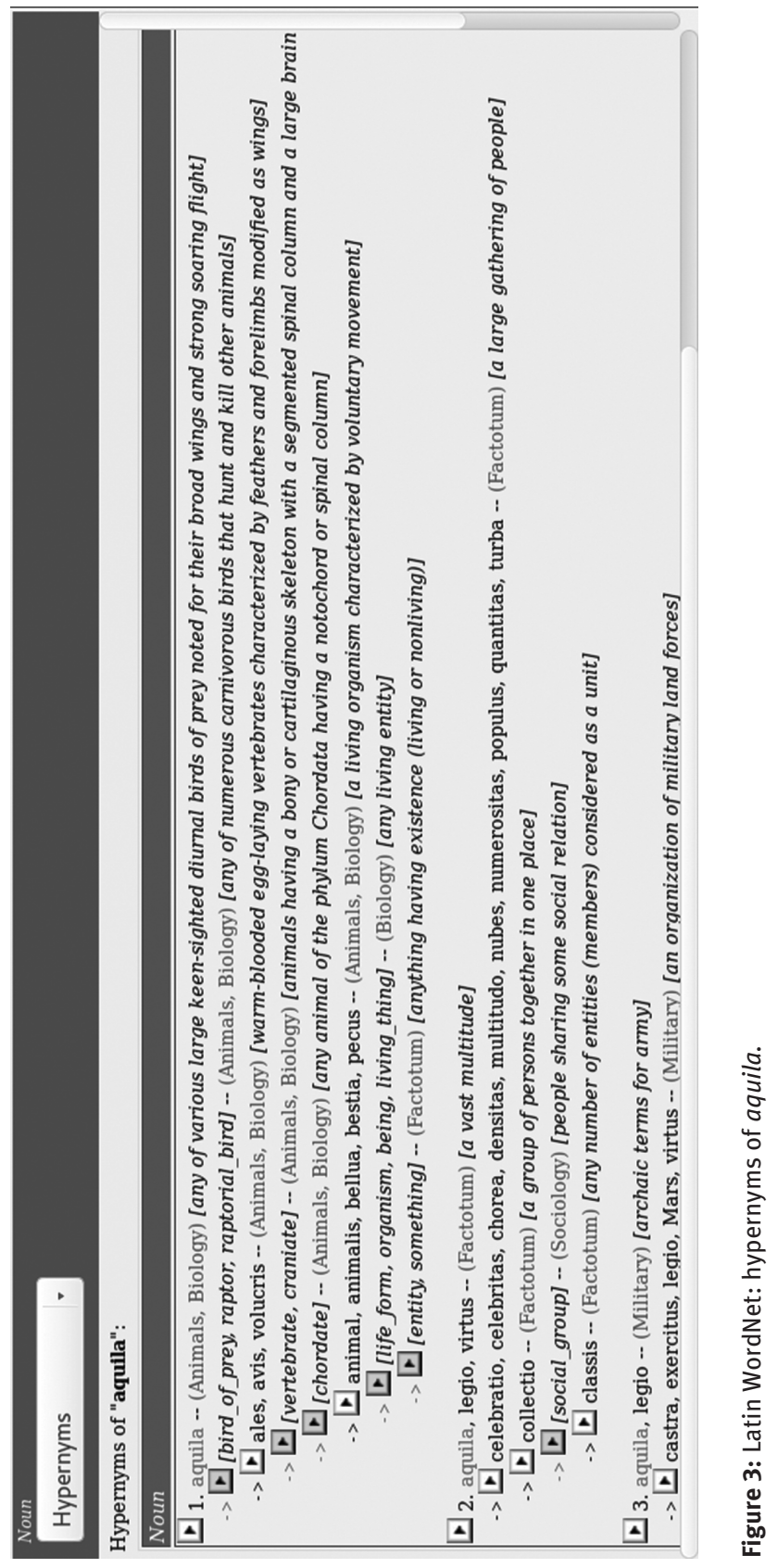


network", hyponym of machina, which is in turn, among other senses, a "4wheeled motor vehicle; usually propelled by an internal combustion engine”, hyponym of vehiculum. Thus, LatinWordNet addresses the problem of polysemy from a modernist perspective.

LWN is used to improve search engines with query expansion mechanisms, which take into account synonyms and other semantically related terms. It is a precious resource also for computational linguistic studies. For instance, McGillivray (2014) used LWN to study verbal selectional preferences for the lexical fillers in specific argument roles. Thanks to the relations of hypernymy / hiponymy,it is possible to identify semantic categories (such as food or drink) preferred by verbs (such as edo or bibo) for the argument roles (such as the affected theme).

\subsubsection{Ancient Greek WordNet}

In collaboration with the Perseus Project and the Alpheios Project, the CNRILC of Pisa is developing Ancient GreekWordNet (AGWN). As described by Bizzoni et al. (2014), three Greek-English digital dictionaries provided by the Perseus Project have been used to bootstrap AGWN: the Liddell-Scott-Jones, ${ }^{9}$ the Middle-Liddell ${ }^{10}$ and Autenrieth's Homeric Lexicon. ${ }^{11}$ Greek words have been grouped in synsets, thanks to the common English translation, and they have been linked by the relation of near equivalence to the synsets in PWN containing the same English word. In this way, the conceptual nodes of AGWN are independent from the conceptual node of PWN, even if they are interlinked, and they can receive a different gloss, more appropriate for the ancient world.

By exploiting WordNet Domains, ${ }^{12}$ which associate each synset of PWN to a specific domain (or to the generic factotum domain), synsets related to modern concepts in chemistry, computer science, telecommunication etc. have been automatically filtered out. For instance, the English word bat assumes in different domains specific senses, glossed by "a nocturnal mouselike mammal [...]" in the domain of Animals and Biology and glossed by "an implement used in baseball by the batter" in the domain of Baseball. The latter sense can be filtered out by the identification of the anachronistic domain, so that the

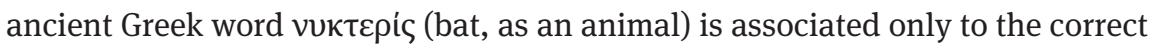
conceptual node, whose gloss is modified in "a nocturnal mouselike animal"

9 See Liddell et al. (1940).

10 See Liddell and Scott (1889).

11 See Autenrieth (1891).

12 See Bentivogli et al. (2004). 
(as shown in Figure 4). Indeed, LWN can have a modernist perspective, because Latin is still in use (e.g. to write encyclicals on current topics), whereas Ancient Greek WordNet must be focused only on the conceptual representation of the ancient world.

gloss (from PWN and manually

modified): nocturnal mouselike

animal with wings

domains: Animals, Biology

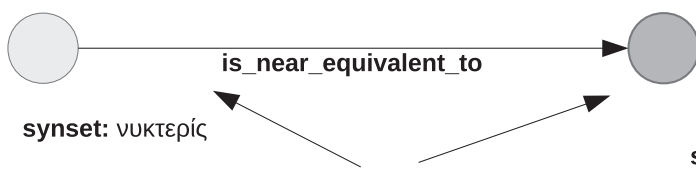

gloss: nocturnal mouselike mammal with forelimbs modified to form membranous wings and anatomical adaptations for echolocation

by which they navigate

synset: bat, chiropteran

Grc-Eng couple extracted from

bilingual dictionaries: vUKTعpís : bat

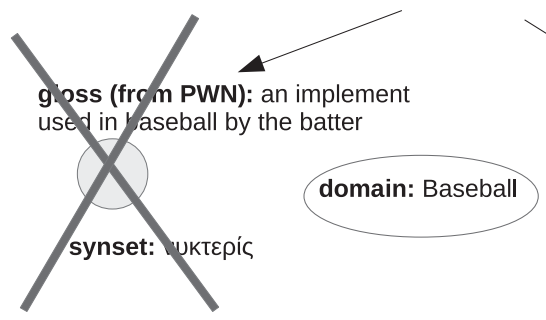

gloss: an implement used in baseball by the batter

Figure 4: Linkage between AGWN and PWN.

Misaligned polysemy between ancient Greek and English and residual anachronisms remain the main source of error: the current version of AGWN, available at http://www.languagelibrary.eu/new_ewnui, is just experimental and still very noisy.

\subsubsection{Homeric Greek WordNet}

From the original Ancient Greek WordNet, a narrower project has been developed on the Homeric lexicon. The Homeric Greek WordNet filters only the synsets that contains at least one word attested in the Iliad, the Odyssey or both the poems.

By focusing our attention on a single author, we had the following goals: a) synchronic perspective on the archaic period; b) usage of a specific sense supported by textual evidence as in historic dictionaries; c) limited number of synsets to check. The ongoing project, accessible at http://cophilab.ilc.cnr.it/hgwnWeb/, engages students for the validation of synsets (last access 2019.01.31). 
As shown in Figure 5, first of all students must check if the synset is active or not (because it expresses an anachronism), if the synset is near equivalent (the default) or loosely approximated to the correspondent PWN and they may modify the gloss accordingly. Then, they must score the pertinence of each Greek word, according to the following scale: a) word unrelated with the meaning of the synset; b) word vaguely related to the synset due to any undeclared reason; c) word that is not synonym but establishes another semantic relation (declared in the notes) with the remaining words of the synset; d) word that fits the meaning of the synset, but is posthomeric; e) word that fits the meaning of the synset and is attested in Homer in that specific sense, as declared in the notes.

\subsubsection{Dynamic Lexicon}

The Dynamic Lexicon ${ }^{13}$ is based on syntactic annotated corpora (treebanks), aligned with modern translations at the granularity of word (or phrase) to word (or phrase). The Dynamic Lexicon (DL), currently extended also to ancient Greek, allows to study collocations, verbal valency, argument structures and selectional preferences.

Considering that both $\mathrm{AGWN}$ and the DL are multilingual resources to study the lexicon of Ancient Greek texts and their translations, and considering that both are works in progress, Berti et al. (2016) combined them, in order to improve the accuracy by mutual correction.

\section{Thematic annotation}

Thematic annotation is performed on the syntagmatic axis by the identification of general topics (themes) and their recurrent, concrete or symbolic actualizations (motifs), even if the definition and distinction of theme and motif is quite controversial. ${ }^{14}$ The main advantages are the possibility to explore the documents of a large corpus by thematic similarities and the possibility to compare multilingual texts, independently by their lexical content. In this section three different approaches are discussed: the first is an automated method to group documents according to word clusters; the others are manual methods to annotate texts: in particular, the second is a top-down approach in which the index

13 See Bamman and Crane (2008).

14 See Segre (1985) and Ciotti (2014). 


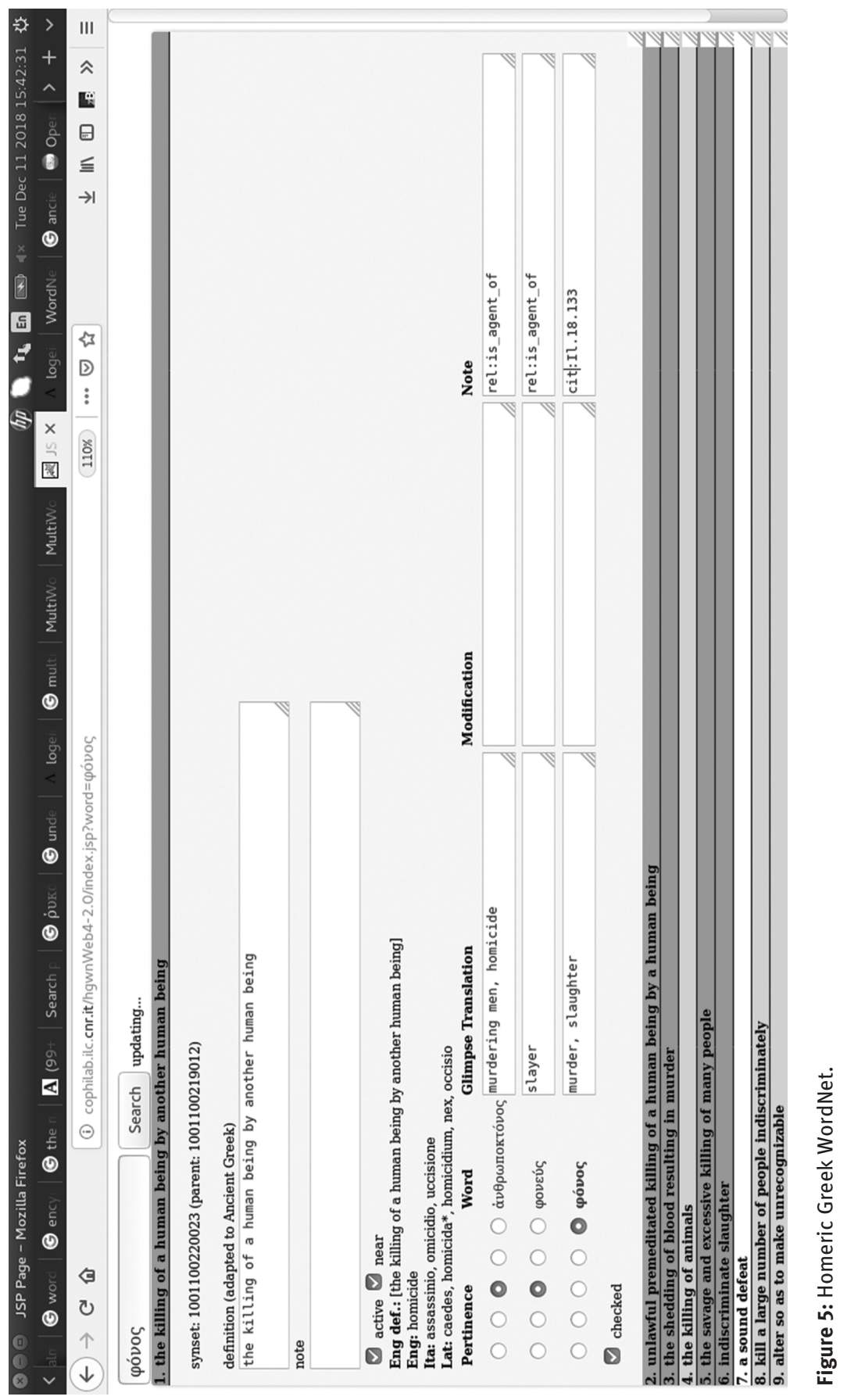


of themes and motifs are established a priori, and the third is a bottom-up approach in which texts are annotated by an open set of descriptors, reorganized a posteriori in ontologies.

\subsection{Topic modeling}

As pointed out in Koentges (2016):

Topic modelling is "a method for finding and tracing clusters of words (called 'topics' in shorthand) in large bodies of texts". A topic can be described as a recurring pattern of cooccurring words. Topic models are probabilistic models that are often based on the number of topics in the corpus being assumed and fixed. The simplest and probably one of the most frequently applied topic models is the latent Dirichlet allocation (LDA).

Topic modeling is useful to identify similarities between documents and to find surprising outliers that need more investigation in large textual corpora, according to the principles of the distant reading. ${ }^{15}$

\subsection{Top-down approach}

A top-down approach to manual annotation of themes and motifs is based on a basic knowledge of the corpus that must be annotated as whole and a solid (literary, linguistic, stylistic, etc.) theory built on previous studies or created on samples of the same or analogous corpora.

A top-down approach is suitable to extend large corpora with new annotated documents according to homogeneous criteria and clear guidelines. As an example, below we present a project that follows this paradigm.

\subsubsection{Memorata Poetis}

Memorata Poetis ${ }^{16}$ is a large intertextual project based on the annotation of themes and motifs related to short poems (e.g. epigrams or sonnets) in ancient Greek, Latin, Italian, English and Arabic literature.

The principal investigator (from the Univesity Ca' Foscari in Venice) established with his collaborators an index of themes and motifs at the beginning of

15 See Moretti (2013).

16 See Mastandrea (2017). 
the project, after a preliminary study of thematic repertories of the last centuries. The index is hierarchically structured in three levels, and the top level is constituted by these six topics: Animalia, Arbores et virentia, Dei et heroes, Homines, Loca, Res. The intermediate level specifies the upper one; for example Arbores et virentia is divided in Arborum species, Flores, Fructus, Usus arborum, herbarum, florum et fructuum. Finally, the lowest level provides the highest degree of details. For example, Flores is divided into Crocus, Flores deis deabusque consecrati, Flores in mythologia, Hyacinthus, Laus florum, Lilium, Metamorphosis in flores, Narcissus, Papaver, Rosa, Serta florum, Viola.

As shown in Figure 6, it is possible to run search on the multilingual, annotated corpus of Memorata Poetis, in order to find co-occurrent themes and motifs: in this specific case for the individuation of the co-occurence of the floral motifs rose and violet, independently by their lexical expression in the different

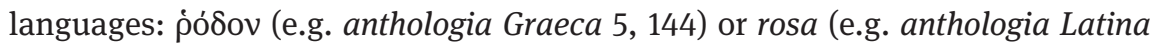
24) for the rose and $\lambda \varepsilon v$ kóıv (e.g. anthologia Graeca 5, 144), lov (e.g. anthologia Graeca 4, 2) or violae (e.g. anthologia Latina 24) for the violet.

\begin{tabular}{|c|c|c|c|}
\hline \multicolumn{4}{|c|}{$\begin{array}{l}\text { VOCI CERCATE: } \\
\text { - Arbores et virentia } \cdot \text { Flores - Viola AND (entro } 10 \text { versi) } \\
\text { - Arbores et virentia } \cdot \text { Flores } \cdot \text { Rosa }\end{array}$} \\
\hline \multicolumn{3}{|l|}{ COLLEGAMENTI TROVATI: 1-13 di 13} & Ritorna alla ricerca \\
\hline Testo & Nodo & Versi & \\
\hline anthologia Graeca, liber 4, 2 & $\begin{array}{l}\text { Viola } \\
\text { Rosa }\end{array}$ & $\begin{array}{l}12 \\
10\end{array}$ & \\
\hline anthologia Graeca, liber 5, 144 & $\begin{array}{l}\text { Viola } \\
\text { Rosa }\end{array}$ & $\rightarrow 1$ & \\
\hline anthologia Graeca, liber 5, 147 & $\begin{array}{l}\text { Viola } \\
\text { Rosa }\end{array}$ & $\geqslant 1$ & \\
\hline anthologia Graeca, Iiber 12, 256 & $\begin{array}{l}\text { Viola } \\
\text { Rosa }\end{array}$ & $>4$ & \\
\hline carmina epigraphica, $1409=$ app. 238 & $\begin{array}{l}\text { Viola } \\
\text { Rosa }\end{array}$ & $\begin{array}{l}\text { intero } \\
\text { intero }\end{array}$ & \\
\hline carmina epigraphica, 2005 = app. 236-237 & $\begin{array}{l}\text { Viola } \\
\text { Rosa }\end{array}$ & $\begin{array}{l}\text { intero } \\
\text { intero }\end{array}$ & \\
\hline Venantius Fortunatus, caminum libri 6, 1 & $\begin{array}{l}\text { Viola } \\
\text { Rosa }\end{array}$ & $\begin{array}{l}\rightarrow 60 \\
>61\end{array}$ & \\
\hline anthologia Latina, 24 & $\begin{array}{l}\text { Viola } \\
\text { Rosa }\end{array}$ & $\begin{array}{l}\square \\
\square 3\end{array}$ & \\
\hline anthologia Latina, 286 & $\begin{array}{l}\text { Viola } \\
\text { Rosa }\end{array}$ & $\begin{array}{l}\longrightarrow p 47 \rightarrow 153-155 \\
\rightarrow p 46 \gg 150-152\end{array}$ & \\
\hline anthologia Latina, 393 & $\begin{array}{l}\text { Viola } \\
\text { Rosa }\end{array}$ & $\begin{array}{l}\rightarrow 8 \\
18\end{array}$ & \\
\hline anthologia Latina, 481 & $\begin{array}{l}\text { Viola } \\
\text { Rosa }\end{array}$ & $\begin{array}{l}\longrightarrow p 34 \not 193-198 \\
\triangleright p 35 \triangleright 199-204\end{array}$ & \\
\hline $\begin{array}{l}\text { carmina epigraphica, Bücheler - Lommatzsch, CLE } \\
00029\end{array}$ & $\begin{array}{l}\text { Viola } \\
\text { Rosa }\end{array}$ & $\mapsto 7$ & \\
\hline Giovanni Gioviano Pontano, de tumulis 2, 24 & $\begin{array}{l}\text { Viola } \\
\text { Rosa }\end{array}$ & $\rightarrow 2$ & \\
\hline
\end{tabular}

Figure 6: Memorata Poetis Search Engine.

A hierarchical index of themes and motifs established a priori, which uses Latin as metalanguage, was necessary to assign clear guidelines for the annotation to 
large and heterogeneous groups of collaborators to the project, but it has drawbacks.

The first is due to the aprioristic creation of the index, that can be only exceptionally modified along the project. The second, strictly related with the first, is due to the adaptation of the observed phenomena to the descriptors available in the model, instead of an adaptation of the model to the observed phenomena. The last drawback is due to the hierarchical structure of the index, which inhibits traversal relations. For instance, Laudes animalium (praises of animals) is under Animalia and Laus florum (praise of flowers) is under Arbores et virentia > Flores, without a link between them.

\subsection{Bottom-up approach}

The knowledge acquired on the themes and motifs actually contained in the corpus of Memorata Poetis Project during the annotation phase and the study a posteriori of the relevant traversal relations among the items of the index are the basis for the ontological reorganization of the index discussed by Khan et al. (2016) for a more efficient querying of the corpus by the integration of textual content, annotations according to the original taxonomy and new ontological information. For example, acts of speech, such as praises, have been identified and grouped in order to be used in query expansions, independently from the object of the praise.

\subsubsection{Euporia}

Taking advantage of this experience and following new trends in manual annotation popularized by CATMA (http://catma.de), we applied a bottom-up approach for research and educational purposes through the annotation tool Euporia. ${ }^{17}$ Euporia is based on Domain-Specific Languages (DSLs) to define the syntax of the annotations, on the CITE (http://cite-architecture.github.io/ about) framework for the stand-off reference to the target texts, on open tagsets (personomies, defined by a single scholar or folksonomies, defined by teams), refined during periodical revisions and, finally, on the identification of ontological relations among the items of the eventual tagset.

17 See Mugelli et al. (2016). 
Figure 7 illustrates the annotation by G. Mugelli to Aesch. Ag. 228-237. The DSL created in collaboration with the LAMA Lab (University of Pisa) for the study of rituals in the ancient Greek tragedies permits the annotation of continuous, discontinuous or overlapping textual sequences by hashtags belonging to an open tagset related to objects, actions, properties involved in rituals presented or mentioned on the stage. The DSL allows the annotation of variant readings (marked by @vl, varia lectio), alternative interpretations (marked by @vi, varia interpretatio) and conditional readings or interpretations (marked in curly braces and possibly negated by the exclamation mark), in order to define constraints for new readings or interpretations.

\begin{tabular}{|c|c|}
\hline 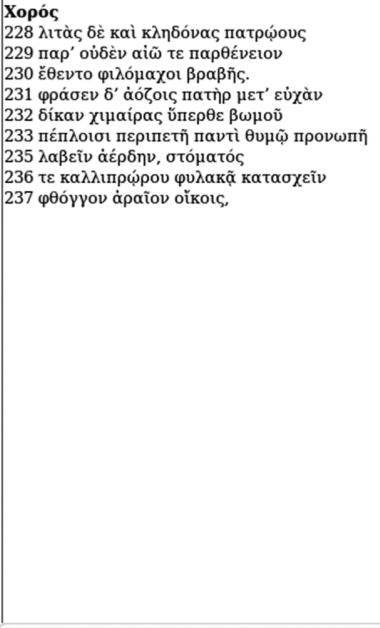 & 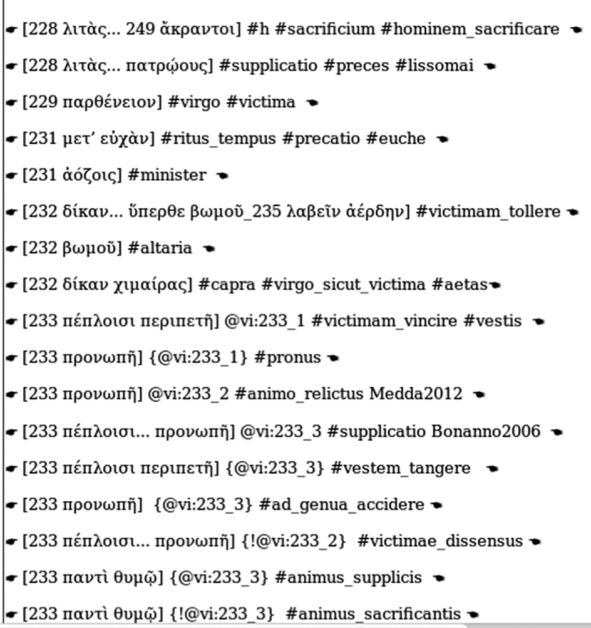 \\
\hline
\end{tabular}

Figure 7: Euporia Annotation.

For instance,

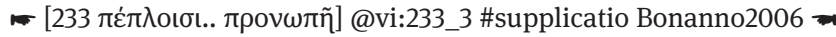

means that Bonanno (2006) suggests to interpret the verse as a supplication and

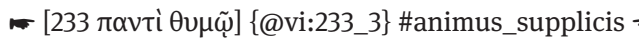

means that, if we accept the Bonanno's interpretation, $\pi \alpha \nu \tau i$ $\theta u \mu \tilde{\omega}$ is referred to a suppliant, otherwise, if we do not accept Bonanno's interpretation, as expressed by

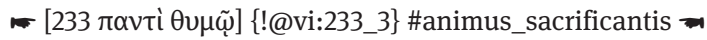

then $\pi \alpha v \tau i$ $\theta u \mu \tilde{\omega}$ should be referred to a sacrificer.

As described by Khan et al. (2018), the personomy (i.e. the open tagset created by G. Mugelli) is linked to an upper ontology for common concepts and to 
a domain ontology for the specific concepts related to rituals in ancient Greek tragedies. By exploiting both the ontological relations (e.g. the relation is_a_type_of) and the original hashtags, the search engines allows query expansion, as shown in Figure 8, in which different types of animals are searched as raised victims in a sacrifice.

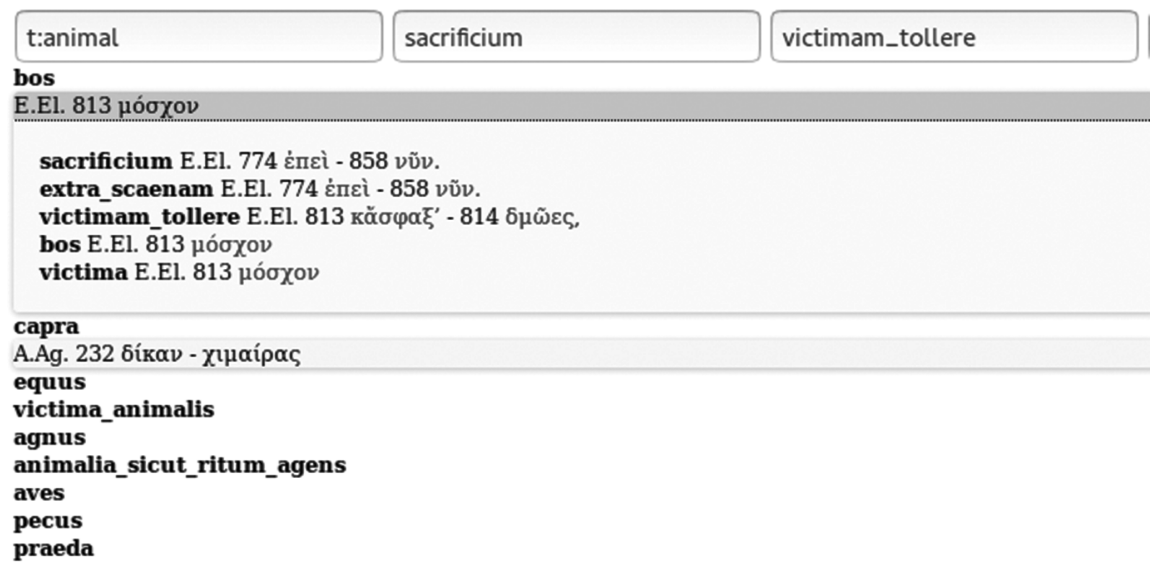

Figure 8: Euporia Search.

\section{Conclusion}

In conclusion, we discussed semantic investigations based on a variety of methods, at different levels of granularity (words or discourse) and with different degrees of automation. All these methods should be considered exploratory, in order to identify regions of interest inside monolingual or multilingual (sub)corpora.

\section{Bibliography}

Autenrieth, G. (1891): A Homeric Dictionary for Schools and Colleges. New York, NY: Harper and Brothers.

Bamman, D.; Crane, G.R. (2008): “Building a Dynamic Lexicon from a Digital Library”. In: Larsen; A. Paepke; J. Borbinha; M. Naaman (eds.): Proceedings of JCDL'08, Pittsburgh, PA, June 16-20, 2008. New York, NY: ACM.

Bentivogli, L.; Forner, P.; Magnini, B.; Pianta, E. (2004): “Revising WordNet Domains Hierarchy: Semantics, Coverage, and Balancing”. In: G. Sérasset; S. Armstrong; C. Boitet; 
A. Popescu-Belis; D. Tufis (eds.): COLING 2004. Proceedings of the Workshop on Multilingual Linguistic Resources (MLR2004), Geneva, Switzerland, August 28, 101-108.

Berti, M.; Crane, G.R.; Yousef, T.; Bizzoni, Y.; Boschetti, F.; Del Gratta, R. (2016): Ancient Greek WordNet meets the Dynamic Lexicon: The Example of the Fragments of the Greek Historians. In: V.B. Mititelu; C. Forăscu; C. Fellbaum; P. Vossen (eds.): Proceedings of the Eighth Global WordNet Conference, Bucharest, Romania, January 27-30, 2016, 34-38.

Bizzoni, Y.; Boschetti, F.; Del Gratta, R.; Diakoff, H.; Monachini, M.; Crane, G.R. (2014): “The Making of Ancient Greek WordNet”. In: N. Calzolari; K. Choukri; T. Declerck; H. Loftsson; B. Maegaard; J. Mariani; A. Moreno; J. Odijk; S. Piperidis (eds.): Proceedings of LREC 2014. Reykjavik: ELRA, 1140-1147.

Bonanno, M.G. (2006): “Assenza, più acuta presenza. Ifigenia nell'«Agamennone» di Eschilo”. Lexis 24, 199-210.

Boschetti, F. (2018): Copisti Digitali e Filologi Computazionali. Roma: CNR Edizioni. http://hdl.handle.net/20.500.11752/OPEN-89 (last access 2019.01.31).

Chomsky, N. (1965): Aspects of the Theory of Syntax. Cambridge, MA: MIT Press.

Ciotti, F. (2014): “Tematologia e metodi digitali: Dal markup alle ontologie”. In: B. Alfonzetti; G. Baldasarri; F. Tomasi (eds.): I cantieri dell'italianistica. Ricerca, didattica e organizzazione agli inizi del XXI secolo. Roma: Adi editore, 1-10.

Egger, C. (2004): Lexicon Recentis Latinitatis. Città del Vaticano: Libraria Editoria Vaticana. Fellbaum, C. (1998): WordNet: An electronic lexical database. Cambridge, MA: MIT Press. Firth, J.R. (1957): Papers in Linguistics 1934-1951. London: Oxford University Press. Hymes, D. (1966): “Two Types of Linguistic Relativity”. In: W. Bright (ed.): Sociolinguistics. The Hague: Mouton, 114-158.

Khan, A.F.; Arrigoni, S.; Boschetti, F.; Frontini, F. (2016): "Restructuring a Taxonomy of Literary Themes and Motifs for More Efficient Querying”. MATLIT: Materialities of Literature 4:2, 11-27.

Khan, A.F.; Mugelli, G.; Boschetti, F.; Frontini, F.; Bellandi, A. (2018): “Using Formal Ontologies for the Annotation and Study of Literary Texts". In: AIUCD 2018 - Book of Abstracts, 31 January - 2 February 2018, Bari: Associazione per l'Informatica Umanistica e la Cultura Digitale, 246-248.

Koentges, T. (2016): "Topic Modelling of Historical Languages in R". https://www.dh.uni-leipzig.de/wo/topic-modelling-of-historical-languages-in-r (last access 2019.01.31).

Lenci, A. (2008): “Distributional Semantics in Linguistic and Cognitive Research”. Italian Journal of Linguistics 20:1, 1-31.

Liddell, H.G.; Scott, R. (1889): An Intermediate Greek-English Lexicon. Oxford: Clarendon Press. Liddell, H.G.; Scott, R.; Jones, H.S.; McKenzie, R. (1940): A Greek-English Lexicon. Oxford: Clarendon Press.

Mastandrea, P. (ed.) (2017): Strumenti digitali e collaborativi per le Scienze dell’Antichità. Venezia: Edizioni Ca' Foscari.

McGillivray, B. (2014): Methods in Latin Computational Linguistics. Leiden and Boston: Brill Mikolov, T.; Sutskever, I.; Chen, K.; Corrado, G.; Dean, J. (2013): "Distributed Representations of Words and Phrases and their Compositionality”. In: C.J.C. Burges; L. Bottou; M. Welling; Z. Ghahramani; K.Q. Weinberger (eds.): Proceedings of the 26th International Conference on Neural Information Processing Systems - (NIPS'13), Volume 2. Curran Associates Inc., USA, 3111-3119. arXiv:1310.4546 [cs.CL]. 
Minozzi, S. (2009): “The Latin WordNet Project”. In: P. Anreiter; M. Kienpointner (eds.): Latin Linguistics Today. Akten des 15. Internationalem Kolloquiums zur Lateinischen Linguistik. Innsbruck: Institut für Sprachen und Literaturen der Universität Innsbruck, 707-716.

Mondin, L. (2014): Introduzione allo studio del latino. Venezia. https://www.docsity.com/it/in troduzione-allo-studio-del-latino/616038 (last access 2019.01.31).

Moretti, F. (2013): Distant Reading. London: Verso.

Mugelli, G.; Boschetti, F.; Del Gratta, R.; Del Grosso, A.M.; Khan, A.F.; Taddei, A. (2016): "A User-Centred Design to Annotate Ritual Facts in Ancient Greek Tragedies". Bulletin of the Institute of Classical Studies 59:2, 103-120.

O’Donnell, M.B. (2005): Corpus Linguistics \& The Greek of the New Testament. Seffield, TN: Sheffield Phoenix Press.

Pianta, E.; Bentivogli, L.; Girardi, C. (2002): “MultiWordNet: Developing an Aligned Multilingual Database". In: Proceedings of the First International Conference on Global WordNet, Mysore, India, January 21 -25.Global WordNet Association.

Rodda, M.A.; Lenci, A.; Senaldi, M.S.G. (2017): "Panta rei: Tracking Semantic Change with Distributional Semantics in Ancient Greek”. Italian Journal of Computational Linguistics 3:1, 11-24.

Segre, C. (1985): “Tema/motivo". In: Avviamento all'analisi del testo letterario. Torino: Einaudi, 331-356.

Vossen, P. (ed.) (1998): EuroWordNet: A Multilingual Database with Lexical Semantic Networks. Dordrecht: Kluwer. 
